\title{
Спринталга в технологии раннего производства лука репчатого
}

\author{
Sprintalga in the technology for early production of a bulb onion
}

\section{Степанов Н.Н.}

\section{Аннотация}

Лук репчатый - одна из самых распространенных овощных культур в мире. В Ростовской области он занимает первое место по посевным площадям среди других овощных культур. Увеличение объемов производства лука репчатого происходит не только за счет увеличения площадей, но и за счет роста урожайности. Кроме того, для увеличения урожая раннего лука необходимо подбирать сорта и гибриды, совершенствовать технологии их выращивания. Одним из важных приемов при выращивании лука в ранней культуре может стать применение в подкормках биологически активных веществ, которые позволяют корректировать процессы роста и развития растений лука, активизировать процесс питания и перемещения питательных веществ в растении. В связи с этим, были проведены специальные исследования по изучению влияния на культуру лука репчатого наиболее распространенного агрохимиката, содержащего свободные аминокислоты и другие активные компоненты - препарата Спринталга. Основной целью исследований было изучение действия препарата Спринталга на процессы роста, развития и продуктивность растений раннеспелого гибрида лука репчатого $\mathrm{F}_{1}$ Бонус в однолетней культуре из семян. Исследования проводили на полях ИП Дигай, расположенного в Азовском районе Ростовской области в 2016-2017 годах. Почвы в опытах - чернозем обыкновенный. Мощность гумусового горизонта - 70 см, содержание гумуса в пахотном горизонте - 3,77\%, содержание подвижных форм питательных элементов - высокое, pH - 7,3. Погодные условия характеризовались значительными перепадами основных метеофакторов в течение всего вегетационного периода лука. Лук возделывался на орошении через капельную систему с фертигацией. Поливная вода имела уровень минерализации от 0,65 г/л весной, до 1,3 г/л в жаркий засушливый период летом. В ходе работы было установлено положительное влияние использования препарата Спринталга в технологии выращивания раннего гибрида лука репчатого $\mathrm{F}_{1}$ Бонус в однолетней культуре из семян. Обработка семян в дозе 0,4 мл на 1 кг семян увеличивает полевую всхожесть на 6\% и способствует лучшей сохранности растений к уборке. Подкормка вегетирующих растений лука в период формирования 2-3 и 5-7 листьев способствует росту урожайности на 2,5-3,1 т/га, повышает товарность и качество лука-репки.

Ключевые слова: лук репчатый, агрохимикат Спринталга, обработка семян, подкормки, урожайность, качество.

Для цитирования: Степанов Н.Н. Спринталга в технологии раннего производства лука репчатого // Картофель и овощи. 2020. №4. C. 14-17. https://doi.org/10.25630/PAV.2020.92.97.003

\section{Stepanov N.N.}

\section{Abstract}

Onion is one of the most common vegetable crops in the world. In the Rostov region it takes the first place among other vegetable crops in cultivated areas. The increase in production of onion is not only due to the increase in acreage, but also due to the growth of productivity. In addition, for increasing the harvest of early onion is necessary to select varieties and hybrids, to improve the technology of their cultivation. One of the most important methods for growing early onion in the culture could be the application of a dressing of biologically active substances which allow to adjust the processes of growth and development of plants of onion, to activate the process of feeding and movement of nutrients in the plant. In this regard, conducted special studies of the culture onion is the most common agrochemical containing free amino acids and other active components of the drug Sprintalga. The aim of the research was to study the action of the drug Sprintalga the processes of growth, development and productivity of plants early-maturing hybrid onion Bonus F1 in the annual culture of seeds. Research conducted in the fields of IP Digi located in the Azov district of Rostov region in 20162017. The soil in the experiments - a common Chernozem. The humus layer of $-70 \mathrm{~cm}$, the humus content in the arable horizon of $3.77 \%$, the content of mobile forms of nutrients - high, $\mathrm{pH}$ of 7.3 Weather conditions were characterized by considerable fluctuations of the main meteorological factors during the growing period of onion. Onion cultivated using drip irrigation system with fertigation. Irrigation water had a salinity of $0.65 \mathrm{~g} / \mathrm{l}$ in the spring to $1.3 \mathrm{~g} / \mathrm{l}$ in hot dry period in summer. During the work was the positive effect of the use Sprintalga in early growing technologies hybrid onion Bonus $F_{1}$ in one culture from the seeds. Seed treatment in the dose of $0.4 \mathrm{ml}$ per 1 $\mathrm{kg}$ of seeds increases the field germination on $6 \%$ and contributes to the better preservation of plants to harvest. Feeding vegetative plants onions during the formation of the 2-3 and 5-7 leaves promotes the growth of crop yields at 2.5-3.1 t/ha, increases the marketability and quality archery.

Key words: onion, Sprintalga, seed processing, fertilizing, harvest, quality products.

For citing: Stepanov N.N. Sprintalga in the technology for early production of a bulb onion. Potato and vegetables. 2020. №4. Pp. 1417. https://doi.org/10.25630/PAV.2020.92.97.003 (In Russ.)
Л ук репчатый занимает первое место среди овощных культур по посевным площадям в Ростовской области. Это главная экспортная овощная культура, которая вывозится в промышленные центры Средней полосы России, включая Москву и Калугу [1]. До последнего времени в производстве были исключительно среднеспелые и позднеспелые сорта и гибриды, созревающие в конце августа и сентябре [2]. Поступление на рынок одновременно больших объемов продукции резко снижало реализационные цены на нее и делало культуру низкорентабельной. Появление озимых форм, а также ранних сортов и гибридов позволи- ло удлинить период поступления свежего лука, прежде всего, в ранние сроки. Подбор сортов и гибридов, а также совершенствование технологии их выращивания очень важны для получения высоких и стабильных урожаев раннего лука [3, 4]. Одним из важных приемов при выращивании лука в ранней культуре может стать приме- 
Таблица 1. Хозяйственные признаки лука репчатого $F_{1}$ Бонус при использовании препарата Спринталга (среднее за $2016-2017$ годы)

\begin{tabular}{|c|c|c|c|c|c|}
\hline Вариант & $\begin{array}{l}\text { Вегетационный } \\
\text { период, сут. }\end{array}$ & $\begin{array}{c}\text { Полевая } \\
\text { всхожесть,\% }\end{array}$ & $\begin{array}{l}\text { Густота стояния к } \\
\text { уборке, тыс. шт. }\end{array}$ & $\begin{array}{c}\text { Диаметр луковицы, } \\
\text { см }\end{array}$ & $\begin{array}{l}\text { Число сухих чешуй, } \\
\text { шт. }\end{array}$ \\
\hline $\begin{array}{l}\text { 1. Контроль Фон + замач. } \\
\text { семян в воде }\end{array}$ & 91,0 & 76,0 & 668 & 6,1 & 2,4 \\
\hline $\begin{array}{l}\text { 2. Фон + замач. семян в } \\
\text { Спринталга }\end{array}$ & 89,0 & 80,3 & 721 & 6,9 & 2,5 \\
\hline $\begin{array}{l}\text { 3. Фон + замач. семян в } \\
\text { Спринталга + } 1 \text { подкорм- } \\
\text { ка } 0,3 \text { л/га }\end{array}$ & 88,0 & 80,4 & 722 & 6,9 & 2,7 \\
\hline $\begin{array}{l}\text { 4. Фон + замач. семян в } \\
\text { Спринталга + } 2 \text { подкорм- } \\
\text { ки } 0,3 \text { л/га }\end{array}$ & 87,5 & 80,4 & 722 & 7,0 & 2,7 \\
\hline $\begin{array}{l}\text { 5. Фон + замач. семян в } \\
\text { Спринталга + } 3 \text { подкорм- } \\
\text { ки } 0,3 \text { л/га }\end{array}$ & 91,4 & 80,4 & 723 & 7,3 & 2,5 \\
\hline $\begin{array}{l}\text { 6. Фон + замач. семян в } \\
\text { Спринталга + } 3 \text { подкорм- } \\
\text { ки } 0,5 \text { л/га }\end{array}$ & 94,0 & 80,5 & 726 & 7,1 & 2,2 \\
\hline $\mathrm{HCP}_{05}$ & - & - & 23,54 & 0,43 & 0,19 \\
\hline
\end{tabular}

нение в подкормках агрохимикатов, содержащих свободные аминокислоты, полисахариды и другие биологически активные вещества, позволяющие корректировать процессы роста и развития растений лука, активизировать процесс питания и перемещения питательных веществ в растении. Особенно эффективны подобные агрохимикаты в условиях стресса: действия экстремальных температур, полива минерализованной водой и других стрессоров, характерных для зоны Северного Кавказа [5].

В связи с этим были проведены специальные исследования по изучению влияния на культуру лука репчатого наиболее распространенного агрохимиката, содержащего свободные аминокислоты и другие активные компоненты - препарата Спринталга.
Цель исследований: оценка действия препарата Спринталга на процессы роста, развития и продуктивность растений раннеспелого гибрида лука репчатого $\mathrm{F}_{1}$ Бонус в однолетней культуре из семян.

\section{Условия, материалы и методы} исследований

Исследования проводили 20162017 годах на полях ИП Дигай, расположенного в Азовском районе Ростовской области. Почва в опыте чернозем обыкновенный. Мощность гумусового горизонта - 70 см, содержание гумуса в пахотном горизонте - 3,77\%, содержание подвижных форм питательных элементов высокое, pH 7,3. Лук возделывали на орошении через капельную систему с фертигацией. Поливная вода имела уровень минерализации от 0,65 г/л весной, до 1,3 г/л в жаркий засушливый период летом. Климат носит резко континентальный характер. Погодные условия характеризовались значительными перепадами основных метеофакторов в течение всего вегетационного периода возделывания культуры.

Технология выращивания лука репчатого - принятая для зоны с использованием препарата Спринталга согласно схеме опытов [2, 4]. Предшественник в опытах - озимая пшеница по пару. После уборки предшественника провели несколько лущений стерни и глубокую зяблевую вспашку, под которую вносили комплексное удобрение $\mathrm{N}_{19} \mathrm{P}_{19} \mathrm{~K}_{19}$ из расчета 130 кг д.в. на 1 га. Весной проводили предпосевную культивацию на глубину 5 см. Посев в конце

Таблица 2. Урожайность и качество лука-репки гибрида $F_{1}$ Бонус при использовании препарата Спринталга (2016-2017 годы)

\begin{tabular}{|c|c|c|c|c|c|c|}
\hline \multirow[b]{2}{*}{ Вариант } & \multicolumn{3}{|c|}{ Общая урожайность, т/га } & \multirow{2}{*}{$\begin{array}{c}\text { Содержание } \\
\text { товарной фракции, } \\
\%\end{array}$} & \multirow{2}{*}{$\begin{array}{c}\text { Средняя масса тов. } \\
\text { луковицы, } г\end{array}$} & \multirow[b]{2}{*}{$\begin{array}{c}\text { Содержание сухого } \\
\text { вещества, \% }\end{array}$} \\
\hline & $\begin{array}{l}2016 \\
\text { год }\end{array}$ & $\begin{array}{c}2017 \\
\text { год }\end{array}$ & $\begin{array}{c}\text { Среднее за два } \\
\text { года }\end{array}$ & & & \\
\hline $\begin{array}{l}\text { 1. Контроль Фон + замач. } \\
\text { семян в воде }\end{array}$ & 73,7 & 73,3 & 73,5 & 80,6 & 88,9 & 9,6 \\
\hline $\begin{array}{l}\text { 2. Фон + замач. семян в } \\
\text { Спринталга }\end{array}$ & 74,7 & 73,5 & 74,1 & 89,8 & 93,5 & 9,3 \\
\hline $\begin{array}{l}\text { 3. Фон + замач. семян в } \\
\text { Спринталга + } 1 \text { подкормка } \\
0,3 \text { л/га }\end{array}$ & 75,3 & 74,9 & 75,1 & 89,9 & 94,8 & 9,2 \\
\hline $\begin{array}{l}\text { 4. Фон + замач. семян в } \\
\text { Спринталга + } 2 \text { подкормки } \\
0,3 \text { л/га }\end{array}$ & 76,5 & 76,1 & 76,3 & 91,0 & 96,4 & 9,1 \\
\hline $\begin{array}{l}\text { 5. Фон + замач. семян в } \\
\text { Спринталга + } 3 \text { подкормки } \\
0,3 \text { л/га }\end{array}$ & 78,3 & 77,7 & 78,0 & 89,8 & 98,1 & 8,9 \\
\hline $\begin{array}{l}\text { 6. Фон + замач. семян в } \\
\text { Спринталга + } 3 \text { подкормки } \\
0,5 \text { л/га }\end{array}$ & 78,9 & 77,5 & 78,2 & 89,4 & 97,5 & 8,9 \\
\hline $\mathrm{HCP}_{05}$ & 2,15 & 2,01 & - & - & 3,55 & - \\
\hline
\end{tabular}


марта на глубину 3,5 см. Норма посева 1 млн шт/га. Схема посева многострочная с технологической колеей: $70+6,5+13+6,5+18+6,5+13+6,5$ см. Капельные линии размещали в междурядьях шириной 13 см. В подкормках использовали комплексное водорастворимое удобрение марки Полифид овощной $\mathrm{N}_{11} \mathrm{P}_{12} \mathrm{~K}_{33} \mathrm{Mg}_{2}+\mathrm{M} Э$, которое вносили через систему фертигации. Подкормки проводили в фазы 2-3 настоящих листьев, 5-7 настоящих листьев и в начале формирования луковиц постепенно повышая концентрацию удобрения с 0,7 до 1,0 и 1,5 г/л поливной воды. По листу подкармливали в период интенсивного нарастания листьев мочевиной в дозе $\mathrm{N}_{10}$.

Схема опытов включала следующие варианты:

1. Контроль: удобренный фон + замачивание семян в воде в течение 12 часов без применения подкормок вегетирующих растений препаратом Спринталга;

2. Удобренный фон + замачивание семян в растворе препарата Спринталга в дозе 0,4 мл на 1 кг семян в течение 12 часов без применения подкормок вегетирующих растений препаратом Спринталга;

3. Удобренный фон + замачивание семян аналогично варианту $2+$ подкормка препаратом Спринталга в дозе 0,3 л/га в фазу 2-3 настоящих листьев;

4. Удобренный фон + замачивание семян аналогично варианту $2+$ двукратная подкормка препаратом Спринталга в дозе 0,3 л/га в фазы 2-3 и 5-7 настоящих листьев лука;

5. Удобренный фон + замачивание семян аналогично варианту $2+$ трехкратная подкормка препаратом Спринталга в дозе 0,3 л/га в фазы 2-3, 5-7 настоящих листьев и в фазу начала формирования луковиц;

6. Удобренный фон + замачивание семян аналогично варианту $2+$ трехкратная подкормка препаратом Спринталга в дозе 0,5 л/га по фазам аналогично варианту 5.

Закладка опытов, учеты и наблюдения проводили в соответствии с Методикой полевого опыта в овощеводстве [6]. Площадь учетной делянки 100 м². Размещение вариантов систематическое, ярусное. Повторность четырехкратная. Препарат Спринталга вносили через систему фертигации.

\section{Результаты исследований}

Проведенные исследования показали, что применение препарата Спринталга в технологии выращива- ния лука репчатого в ранней культуре из семян позволяет стимулировать процессы роста и развития растений лука раннеспелого гибрида $\mathrm{F}_{1}$ Бонус (табл. 1).

Замачивание семян в растворе препарата способствовало увеличению полевой всхожести семян с 75\% в контроле до 80,2-80,4\% в опытных вариантах. Наблюдалось соответствующее увеличение густоты стояния растений лука к уборке на 7,1-7,9\%.

Применение

препарата Спринталга увеличивало размер луковиц. При этом лучшие результаты получены в варианте с замачиванием семян и трехкратной подкормкой в дозе 0,3 л/га (рис.). Количество кроющих чешуй незначительно увеличивалось только при одно- и двухкратной подкормке препаратом Спринталга в начальные периоды роста и развития растений лука. Использование подкормок на более поздней фазе формирования луковицы снижало количество кроющих чешуй.

Основное стимулирующее влияние препарат Спринталга оказал на корневую систему, т.е. на ее поглотительную способность. Наибольшая масса корней наблюдалась в варианте с тремя подкормками в дозе 0,5 л/га.

\section{Библиографический список}

1.Зинченко В.Е. и др. Состояние и перспективы производства лука репчатого в Ростовской области // Интродукция нетрадиционных и редких растений. Материалы V Международной научно-практической конференции. п. Персиановский: ДонГАУ, 2004. С. 71-74.

2.Гиш Р.А., Благородова Е.Н., Лукомец С.Г. Технология выращивания лука репчатого в яровой и озимой культуре на Кубани в условиях малых форм хозяйствования: научно-производственное пособие. Краснодар: КубГАУ, 2012. 48 с.

3.Ховрин А.Н., Монахос Г.Ф. Производство и селекция лука репчатого в России // Картофель и овощи. 2014. №7. C. 18-21.

4.Лук и морковь. Каталог-2011. Волгоград: ОАО Альянс «Югполиграфиздат», 2011. С. 15-19.

5.Хорошкин А.Б. Аминокислоты в листовых подкормках // Картофель и овощи. 2015. №5. С. $17-18$.

6.Литвинов С.С. Методика полевого опыта в овощеводстве. М.: Россельхозакадемия, 2011. 648 с.

\section{Об авторе}

Степанов Николай Николаевич, соискатель, ФГБОУ ВО Донской ГАУ. E-mail: nik1313765@gmail.com

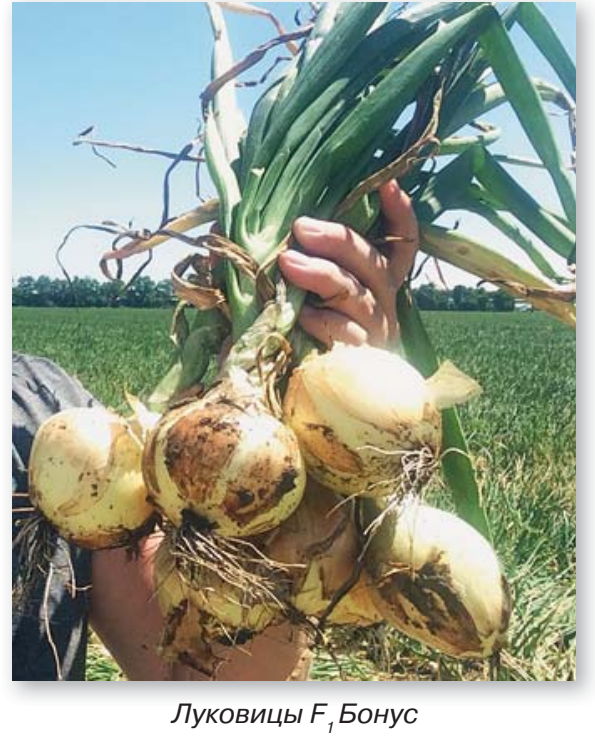

Очень важно влияние препарата Спринталга на продолжительность вегетационного периода растений лука. Сокращение периода принципиально важно для ранней культуры при использовании раннеспелых гибридов типа $F_{1}$ Бонус. Применение препарата Спринталга на ранних фазах роста и развития растений способствовало сокращению вегетационного периода, а при использова-

\section{References}

1.Zinchenko V.E. et al. State and prospects of onion production in the Rostov region. Introduction of non-traditional and rare plants. Materials of the $\mathrm{V}$ International scientific and practical conference. Persianovsky: Don State University, 2004. Pp. 71-74 (In Russ.).

2.Gish R.A., Blagorodova E.N., Lukomec S.G. Technology for growing onions in spring and winter crops in the Kuban in small-scale farming: research and production manual. Krasnodar: Kuban State Agrarian University, 2012. 48 p. (In Russ.).

3. Hovrin A.N., Monahos G.F. Production and selection of onions in Russia. Potato and vegetables. 2014. No7. Pp. 18-21 (In Russ.).

4.Onions and carrots. Catalog-2011. Volgograd: Public corporation «Alliance «Wholegrain», 2011. Pp. 15-19 (In Russ.).

5. Horoshkin A.B. Amino acids in the leaf dressing. Potatoes and vegetables. 2015. No5. Pp. 17-18 (In Russ.).

6.Litvinov S.S. Methods of field experience in vegetable growing. Moscow: Russian Agricultural Academy, 2011. 648 p. (In Russ.).

\section{Author details}

Stepanov N.N., applicant, Don State Agrarian University. E-mail: nik1313765@ gmail.com 
нии в период формирования луковицы, наоборот, его удлиняло. Лучшим вариантом при этом оказался вариант с двухкратной подкормкой препаратом Спринталга в фазы 2-3 и 5-7 настоящих листьев. Сокращение вегетационного периода по сравнению с контролем составило почти четыре дня.

Сказалось применение препарата Спринталга на величине и качестве урожая лука-репки (табл. 2).

В среднем за два года, в сравнении с контролем и вариантом с применением препарата Спринталга только для обработки семян, общая урожайность в вариантах с подкормкой вегетирующих растений возросла на 1,8-4,9 т/га. В тоже время, содержание товарной фракции наиболее высоким оказалось только при подкормках, проведенных на ранних фазах 2-3 и 5-7 листьев. Подкормки в фазу формирования луковицы уменьшали содержание товарной фракции на 0,4-0,8\% по отношению к лучшему варианту с двукратным применением подкормок на ранних фазах. С увеличением кратности обработок Спринталга и повышении концентрации препарата с 0,3 до 0,5 л/га масса луковиц возрастала. Снижение товарной фракции происходило за счет увеличения доли многогнездных луковиц и увеличения пораженности их фузариозом.

Увеличение размеров луковиц сопровождалось снижением содержания сухого вещества, по всей видимости, из-за высокой насыщенности их водой за счет активной деятельности корневой системы. Стимуляция корневой системы при применении препарата Спринталга в период формирования луковиц здесь также приводит к нежелательным последствиям.

\section{Выводы}

Таким образом, в технологии выращивания раннеспелого гибрида лука репчатого $F_{1}$ Бонус в однолетней культуре из семян целесообразно использовать препарат Спринталга. Лучшие результаты обеспечивает обработка семян перед посевом для повышения полевой всхожести и выживаемости растений в дозе 0,4 мл/кг семян и корневые подкормки в фазы 2-3 и 5-7 листьев в дозе 0,3 л/га, что способствует увеличению урожайности на 3,1 т/га при сокращении вегетационного периода до 4 дней при улучшении качества продукции. 